\title{
Research on Long-Term Mechanism of China's Environmental Governance
}

\author{
Shangqin Zhou ${ }^{1}$, Shengxi Guo ${ }^{2}$ \\ ${ }^{1}$ China University of Political Science and Law, Beijing, 100088, China \\ ${ }^{2}$ Hunan Normal University, Changsha, Hunan, 410081, China
}

Keywords: Environmental governance, Environmental protection inspection, Party and government accountability, Performance appraisal, Long-term mechanism

\begin{abstract}
The impetus mechanism of environmental governance is the accountability system. The China's central government adopts the path of environmental protection inspection and implements "shared liability of the party and the government", "bi-liability under single position" and "stringent accountability", which captures the essence of the issue of the environmental governance However, environmental inspection can only work in a short-term manner for environmental governance, and cannot replace the long-term legal system that has been established. It is necessary to avoid the extremes of environmental inspection only. Environmental governance should consciously return to a long-term legal mechanism, with the accountability system as the key pillar, strengthen both legal and political accountability, use environmental protection assessment as a drive mechanism, give play to the political advantages of the environmental protection inspection system, and urge environmental governance entities to perform their duties in accordance with the law, so as to build a long-term mechanism for environmental governance.
\end{abstract}

\section{Introduction}

For a long time, in China, both civil and administrative public interest litigation system have been established based on the environmental legal system as the, forming a relatively complete and stable environmental legal governance system. However, the existing environmental governance system has not produced ideal governance effects. The reasons can be attributed to the following three points. First, the environmental governance system still needs to be explored. There are many loopholes in the current legal governance system, and there are many problems in the legislation, law enforcement, and justice in the field of environmental protection. Although the implementation of the environmental protection inspection system has solved many problems in environmental governance, such short-term governance method cannot provide long-term protection. Second, the direction of government assessment is deviated. Local party committees and governments have long focused their assessments on economic GDP growth and neglected the green GDP based on environmental protection, making environmental protection departments in fact marginalized at all levels of government. Third, the implementation of environmental accountability is not fully in place. For a long time, inactions such as lazy and negligent administration have been common, and environmental accountability systems such as legal and political liabilities have not been functioned. Environmental protection inspection is carried out mainly through political means to implement environmental governance accountabilities, but there are problems of normalization and long-term effectiveness. Looking back on the new round of environmental protection inspection in 2018, it is revealed that environmental governance problems still have "formalistic response, random handling, and disorderly management" in regard to environmental governance. For this reason, some scholars in China have proposed to solve environmental governance problems through the legalization of environmental protection inspections. But can the environmental governance problems be truly and completely solved by the legalization of environmental protection inspections alone? This is questionable.

In the era of comprehensive rule of law, there is no problem in promoting the rule of law in environmental inspections. The problem is that the rule of law in environmental inspections is 
pushed to a commanding height, and the environmental inspection system is used as the core support system of the environmental governance system, which violates The original intention of the design of the environmental protection inspection system itself and also eliminates the most fundamental characteristics of the environmental protection inspection system. As an unconventional system, the environmental protection inspection itself has its characteristics and advantages as "unconventional" itself. Environmental governance is a systematic and complex large-scale project. The design of environmental governance mechanisms should be considered from an overall and systematic perspective, and form a logical structure with distinct priorities, orderly, scientific and rational based on the characteristics, functions and advantages of different institutional elements. The overall structure and institutional design of the environmental governance system cannot be easily denied because of individual superior institutional elements. China's environmental governance mechanism should always adhere to the principle of environmental legal system as the basis, the environmental legal system as the leading framework, combing the environmental protection inspection system, administrative accountability system, and environmental evaluation system to create a long-term environmental governance mechanism.

\section{The Logical Composition of the Current Environmental Governance Mechanism}

China's environmental governance mechanism refers to a series of system designs and measures adopted in the field of environmental protection under the overall layout of ecological civilization incorporated into the "five-in-one" socialist construction with Chinese characteristics. System composition includes environmental protection inspection system oriented to special issues, government indicator evaluation system oriented to governance effects, and administrative accountability system oriented to legal responsibility; governance measures include: party and government accountability, administrative law enforcement, special rectification, etc. The current environmental protection inspection system mainly has problems such as difficulty in implementing inspection measures and poor connection between environmental protection inspections and the legal system. The establishment of a long-term environmental governance mechanism requires an organic combination of environmental law enforcement and environmental protection inspections, and the improvement of environmental protection index assessment and evaluation System, laws and regulations system, environmental protection supervision system, administrative accountability system, form a systematic, normalized and legalized long-term environmental governance mechanism.

\subsection{Environmental Legal System is the Core Foundation of Environmental Governance Mechanism}

China great importance has always been attached to environmental governance and administration in accordance with law, and a large number of environmental protection laws and regulations have been formulated. Since the 1980s, more than 30 laws related to environmental governance have been enacted, including the Environmental Protection Law, the Water Pollution Prevention and Control Law, the Soil Pollution Prevention and Control Law, and the Air Pollution Prevention and Control Law, etc., which constitutes a comprehensive legal system for environmental protection. In 2015, China introduced the "Environmental Protection Law" known as "the most stringent environmental protection law in history". This law strengthens government supervision and management responsibilities, increases punishments for illegal acts, enters the red line of ecological protection into the law, and provides for the clarification on implementation of public co-governance and the like at innovative institution level. At the level of administrative regulations, more than 130 regulations such as the "Regulations on Environmental Impact Assessment for Planning" and "Regulations on Environmental Management of Construction Projects" have been formulated; in terms of departmental regulations and local environmental protection legislation, the number is even greater. In terms of the formulation of environmental standards, there are nearly 2,000 national environmental quality standards. A large-scale and complete system of environmental laws and regulations. Through the standardized system, the basic 
framework, management system and operating mechanism of environmental governance have been established in China. Although the existing environmental governance legal system has many problems such as unclear environmental governance functions, lax law enforcement, false accountability, and ineffective supervision, we cannot completely deny its important role, or even directly replace it with the legalization of the environmental protection inspection system.

\subsection{Environmental Protection Assessment is the Endogenous Driving Force of the Environmental Governance Mechanism}

The assessment of indicators and the construction of ecological civilization were regarded as part of the national governance system in the Third Plenary Session of the Eighteenth Central Committee of the Communist Party of China. In the Fourth Plenary Session of the Eighteenth Central Committee, it was further proposed that "the effectiveness of the construction of ecological civilization is important as a measure of the performance of leading groups and leaders at all levels, and should be included in the performance evaluation index system”. The performance evaluation index system is used as an objective evaluation standard for cadre rewards and promotion, the excellent performance of the evaluation directly determines the reward and promotion of cadres. In the process of continuously promoting the construction of ecological civilization, the status of environmental governance is constantly strengthened in the performance evaluation index system of all levels of government, which makes environmental governance the focus of the government's daily work and promotes the formation of a drive mechanism. The assessment and evaluation of environmental governance mainly go through two paths - one is the administrative accountability mechanism, and the other is the evaluation of performance promotion. The two different paths can form a mechanism of action from two dimensions - negative punishment and active encouragement. In terms of negative punishment, in the case of violating laws and disciplines and being lazy and acting indiscriminately, the responsible person of the party and the government and law enforcement personnel of relevant functional departments shall be held accountable for the political and legal responsibilities of the party and government officials; in terms of positive encouragement, for those who are competent and have contributed to environmental governance and governance, such contribution could be regarded as important basis for reference to rewarding and their promotion. The operating mechanism of the government performance appraisal and environmental governance appraisal echo. The environmental governance appraisal is incorporated into the government performance appraisal index system, forming the essence of the environmental governance mechanism. The effectiveness of environmental protection inspection is remarkable, precisely because of the capture of the essence of environmental governance evaluation and accountability.

\section{Realistic Problems Faced by Environmental Governance in the New Era}

In regard to the practical problems faced by environmental governance in the new era, some scholars have looked for reasons from environmental legislation, administration, justice, and inspections. They believe that China's environmental legislation is contrary to the purpose of environmental protection. There are laws and regulations but no enforcement measures in the field of law enforcement. The costs for sanctions on illegal acts are too low. Some scholars also believe that the government performance appraisal index system has failed to establish an important position in environmental governance, causing some local governments to disregard environmental public interests for the sake of local interests or the personal interests of officials, and long-term performance projects. Inadequate local environmental protection law enforcement and ineffective supervision are the biggest dilemmas in the performance of local environmental protection duties. As political goals and political responsibilities have also become the main theme of environmental governance, it is an inevitable trend to develop from emphasizing the government's supervisory power (oversight of enterprises) to emphasizing the responsibility of the party committee and government (oversight). The authors of this article believe that the biggest problem faced by environmental governance is the coordination of environmental protection inspection requirements, 
government performance appraisal, and administration by law. The specific manifestations are that the campaign-style special rectification is not coordinated with the conventional environmental law enforcement, that the administrative accountability and the party discipline accountability mechanism are not matched, and that the government performance is inconsistent with the environmental governance evaluation value goals.

\subsection{Lack of Coordination among Environmental Governance Organizations}

From the perspective of the unity of the party and government, the current environmental governance system mainly relies on the government's environmental protection functional departments, through regular administrative approval and administrative law enforcement and other legal means. On this basis, the "Environmental Protection Inspection Work Leading Group" established by the State Council and some local governments is mainly to solve the problem of coordination of environmental governance across regions and functional departments, and to strengthen environmental protection law enforcement supervision and implementation of environmental rectification. This agency belongs to the "discussing and coordinating agency" within the administrative agency system of our country, which is different from various permanent administrative agencies with daily functions. In terms of the establishment of powers, the environmental protection supervision work leading group within the government can only manage "politics" but not "party", which is a deviation from the basic principle of "party and government equal responsibility" established by the central government. In June 2019, the Central Ecological Environmental Protection Inspection Work Leading Group was established. In accordance with the requirements of normal institutionalization, the six environmental protection inspection centers under the Ministry of Environmental Protection were transformed from public institutions to dispatched administrative agencies and belonged to the leadership of the central environmental protection inspection work. group. From the perspective of the departmental composition of the Central Supervisory Leading Group, it not only involves party departments and administrative agencies, but also includes procuratorial organs, strengthening all-round party leadership, government coordination, and judicial supervision. But whether it can effectively play the expected "organizational coordination" function remains to be tested in practice. From the perspective of the promotion mechanism, the central environmental protection inspection will no longer carry out environmental protection inspection work through traditional bureaucratic institutions (environmental supervision and law enforcement departments, regional environmental protection inspection centers), but will mobilize and mobilize various resources within the system through a top-down approach, with measures by higher-level authorities strongly promoting environmental protection inspection work and achieving results in a short period of time. This kind of advancing mechanism will inevitably have an impact on the existing environmental governance system, and it becomes the key to properly handle the relationship between government functional departments, local government internal inspection teams, and central inspection teams.

\subsection{Administrative Accountability is Not Compatible with the Party Discipline Accountability Mechanism}

On the whole, the government's environmental protection target responsibility system and assessment system have detailed regulations on the assessment and accountability of governments at all levels and key leaders in completing environmental protection targets, and a comprehensive and systematic legal system of basic internal accountability system has been formed. At the level of the environmental governance legal system, Chapter IX of China's Civil Servants Law and Article 68 of the Environmental Protection Law stipulate legal responsibilities for persons responsible for violating supervisory duties; at the level of internal party regulations, it was launched in June 2019 the first internal party regulation in the field of environmental protection supervision, the "Regulations on the Central Ecological Environment and Environmental Protection Supervision Work" (hereinafter referred to as the "Regulations"). However, the "Regulations" on the accountability of inspectors only generally stipulate that "implement in accordance with relevant regulations", "in accordance with laws and regulations" and so on. The party and government 
accountability adopted by environmental protection inspectors overlaps significantly with the administrative accountability stipulated by existing laws. There is a lack of clear regulations on how the two can be effectively linked, which needs to be further resolved.

\section{Casting a Long-Term Mechanism for Environmental Protection Governance}

From the perspective of the original environmental governance mechanism, it is mainly through clarifying environmental protection responsibilities and environmental law enforcement authorities, using the principle of coordination to carry out institutional reforms, and reducing the proportion of GDP evaluation in performance evaluation. The environmental protection inspection mechanism is mainly based on an authoritative political perspective, with the party and government accountability as the main focus, to solve many problems such as unclear environmental protection responsibilities, failure to implement governance measures, and lack of coordination between departmental law enforcement. To improve the long-term mechanism of environmental governance, focus should be put back to the environmental governance legal system as the main body, the environmental protection inspection system as the supplement, the combination of legal governance and political inspection, and the integration of environmental assessment and comprehensive assessment.

\subsection{Systematization of Party and Government Accountability}

There should be dialectical thinking in understanding the integration of party and government responsibilities, and the connection between the two should not be completely separated. Political responsibility and legal responsibility must be distinguished and unified. Environmental protection inspection involves two levels of "party" and "politics." The normative logic and system functions of legal responsibility and political responsibility should be emphasized and differentiated. The "party" and "political" should not be simply confused, especially In terms of accountability, "the law belongs to the law, and the politics belongs to the politics", the two cannot be substituted for each other. From the perspective of the integration of China's environmental governance system, environmental governance is not only the legal duty of the government, but also the political task of the ruling party. China's political system determines that legal and political responsibilities are interrelated and inseparable, and the two are mutually integrated. .

For one thing, to pursue legal liabilities in accordance with the law. From the perspective of governance system, environmental governance is a systematic project that requires collaboration and coordination among multiple levels of departments. The current environmental governance problem is not the lack of a legal system, but mainly the unscientific governance concept, unclear governance responsibilities, and lack of strict governance measures. According to the "Environmental Protection Law", local people's governments at all levels and relevant departments are responsible for environmental governance, and the central environmental protection inspector accountability is based on whether the government and relevant departments actually perform their statutory duties. It is to strengthen local governments and functional departments to implement the law Responsibility. From the perspective of the effects of environmental protection inspections, local governments and departments at all levels actively cooperated and achieved good governance results. The environmental protection inspection accountability mechanism also reminds us that the key to environmental governance is to activate the functions of the existing legal system and clarify the rights and responsibilities of the responsible entities. Strictly investigate the legal liabilities for acts of negligence, negligence, abuse of power, and other acts. At the same time, further strengthen the role of judicial supervision and social supervision in the environmental governance system, establish a comprehensive legal supervision system and accountability mechanism, and realize governance according to law.

For another, to pursue political responsibility in accordance with regulations. At the political level, the construction of ecological civilization has become an important political task of governments at all levels, and environmental protection inspection has become a kind of government supervision measure within the party. Under the background that the environmental protection inspection system is becoming more and more normalized and institutionalized, it should 
avoid overlapping and conflicting with the existing legal system. If a matter falls within the scope of adjustment of national laws and is regulated by laws and regulations, there is no need to repeat regulations within the party Regulations, avoid conflicts and derogate the authority of the law. China's environmental protection inspectorate should adopt the "party" and "government" separation model. According to the basic principle that "national legislation is higher than internal party regulations, and internal party regulations are stricter than national legislation", corresponding internal party legislation and state legislation should be formulated and improved. Laws, eliminate the current "Regulations" in terms of effectiveness level, applicable objects, and system completeness, provide a systematic legal system and an operational rule system for environmental protection inspection accountability, standardize ecological environmental protection inspection work, and compact environmental governance Political responsibility forms an accountability system that distinguishes and cooperates with accountability according to law and accountability according to regulations.

\subsection{Coordination of Governance Paths}

First, clarify the functional positioning of environmental protection inspectors. The functional positioning of the environmental protection inspection system is the "spur" and "repair" of the Party Central Committee's implementation of the current environmental protection legal system. The spur function mainly refers to the central environmental protection supervision to inspect major issues, individual field issues, strong responses, and adverse impacts. Environmental protection inspections have no intention and cannot replace the existing supervision system of environmental protection systems. They have passed key inspections, supervision, and accountability. Way to ensure that the country's environmental protection decisions and deployments are realized. Both the environmental protection inspection team and the local party committees and governments have different functional powers. In the process of environmental governance, the environmental protection inspection team does not replace the corresponding functional departments of the government, but only conducts "environmental inspection" through accountability methods such as supervision and supervision. The participants should perform their respective duties in the allocation of environmental protection functions, and environmental inspection organizations cannot overintervene or even directly replace local government management activities in the name of environmental protection. The leak-recovery function mainly refers to the situation of cross-basin coordinated governance, environmental protection issues, inaction and disorder, etc., when the implementation of the existing protection legal system has "failures" or "blanks", the environmental protection inspection Ways to make up for it, including problems such as poor coordination of the coordinated governance system, inefficient and negligent reforms, and prevarication of local governments. In terms of role-playing, the central government's implementation of the environmental protection inspection system is, on the one hand, to effectively respond to social conditions and public opinion on key areas and major environmental issues that have a negative impact, and to address environmental issues in a targeted manner through efficient and flexible methods; on the other hand, to implement The strategic deployment of national environmental protection decision-making is to urge all localities to earnestly fulfill their legal responsibilities, to hold local party committees and governments accountable for inaction and disorderly actions, to fully implement the central government's various environmental protection decision-making strategies, and to effectively maintain and protect the lives of the people ,Production Environment. The leak-recovery function of environmental protection inspectors can only appear when the existing legal system cannot meet environmental protection and governance. In other words, it is more accurate to define the environmental protection inspection system as a "substitute member".

Second, coordinated environmental management system. Through institutional reforms, this is a mechanism to facilitate the distribution of environmental power between the central and local governments. In response to the fragmentation of environmental law enforcement by local governments, similar functions have been merged into the comprehensive environmental law enforcement department, referring to the original six "environmental protection inspection centers" 
and under the leadership of the environmental protection inspection team. In terms of institutional reform, refer to the reform model of the Comprehensive Law Enforcement Bureau and the Administrative Approval Bureau, and integrate the functions of the departments with similar environmental protection functions into a unified department. For example, taking into account the outstanding phenomenon of "Jiulong Water Control", the river basin management agency can become the function allocation agency of the provincial and municipal environmental protection and water conservancy departments in a certain river basin protection area. On the basis of the system reform of the comprehensive environmental law enforcement agency, it can be made to not follow the "block-like" institutional management model, and directly accept the direct guidance of the central environmental protection inspection team or office. This requires all competent authorities to recognize the status of "separate plan" of river basin management agencies and let them be "quasi-subordinates". The advantage of this program lies in incorporating such comprehensive environmental management agencies into the current party-government integration system to resolve their policy guidance, projects, and funding. In order to ensure the effective operation of its functions and play the role of the central environmental protection inspector. It not only solves the problem of the upper interface, but also clarifies the rights and responsibilities of the horizontal and other related functional departments. The difficulty is that if this reform is approved, it means that traditional management models will face challenges.

\section{Conclusion}

After summarizing the experience of the current environmental governance mechanism and prudently reflecting on it, a basic conclusion is reached that the improvement of the environmental governance system must rely on a long-term and normalized legal governance mechanism. In terms of environmental governance concepts, we should avoid falling into the misunderstanding of replacing, subverting, and restructuring the environmental governance system through the legalization of environmental protection inspections; in the design of long-term mechanism, we should adhere to the integration of party and government accountability, coordination of action mechanisms, and environmental protection evaluation Scientific; in the logical structure of the mechanism, we should always adhere to the conventional legal system as the main body, maintain and give full play to the unique political attributes of environmental protection inspections, and both play their own advantages and characteristics, cooperate with each other, and integrate with each other to build long-term environmental governance mechanism.

\section{References}

[1] Wang Jin. Analysis of the Failure of China's Environmental Law-Analysis of the Impact of Ruling Factors on China's Environmental Law. Shanghai Transportation Journal of the University, vol. 3, no. 1, pp. 25-29, 2012.

[2] World Wide Web “Environmental Protection Inspectors “Looking Back”: Ten provinces and cities have not been spared the three major chaos", https://baijiahao.baidu.com/s?id=160430293 4048988200\&wfr=spider\&for=pc.

[3] Wang Tiemin. The most stringent laws still need the most stringent enforcement. China National People's Congress, vol. 9, no. 3, pp. 1, 2014.

[4] Sun Youhai. Study on Several Key Points of Ecological Civilization and Rule of Law Innovation in the New Era, Zhongzhou Academic Journal, vol. 2, no. 3, pp. 2, 2018.

[5] Sun Youhai. The Basic Experience and Existing Problems of China's Environmental Legislation Since Reform and Opening Up. China University of Geosciences, vol. 4, no. 2, pp. 42, 2008.

[6] Sheng Ruowei. The head of the Central Organization Department revised and promulgated the Regulations on the Selection and Appointment of Party and Government Leading Cadres” Answers Questions from Journalists. People's Daily January, 17, 2014. 
[7] The announcement of the Fourth Plenary Session of the 18th Central Committee of the Communist Party of China, "Decision of the Central Committee of the Communist Party of China on Several Major Issues Concerning the Comprehensive Promotion of the Rule of Law.”

[8] Cai Shouqiu. On the Defects and Perfection of Government Environmental Responsibilities. Hebei Law Science, vol. 26, no. 3, pp. 18, 2008.

[9] Yu Guanghui and Chen Liang. On the Perfection of China's Environmental Law Enforcement Mechanism: From the Perspective of Regulation Capture. Legal Science, vol. 5, no. 6, pp. 93, 2010.

[10] Wang Canfa, Chen Shiyin. The Justification and Conception of the Codification of China's Environmental Law. Journal of Renmin University of China, vol. 2, no. 33, pp. 1, 2019.

[11] Wang Jin. Analysis of Factors Influencing the Failure of China's Environmental Rule of LawAnalysis of the Influence of Ruling Factors on China's Environmental Rule of Law. Journal of Shanghai Jiaotong University, vol. 1, no. 1, pp. 25-28, 2012.

[12] Luo Wenjun. On the Incentive Mechanism of China's Local Governments to Fulfill Environmental Protection Functions. Shanghai Jiaotong University PhD Dissertation, pp. 36.

[13] Chen Haisong. Policy and Legal Relations in the Transformation of China's Ecological Civilization Rule of Law. Journal of Social Sciences of Jilin University, vol. 2, no. 2, pp. 52, 2020.

[14] Chen Haisong. Legalization of the Environmental Protection Inspection System: Positioning, Dilemma and Way Out. Law Review, vol. 3, no. 6, pp. 181-182, 2017.

[15] Regulations on the Work of the Central Ecological and Environmental Protection Inspectorate. 2019.

[16] Qi Jiangang, Yu Haiyang. On the "Central Environmental Protection Supervision System” as a Sporty Governance Mechanism-Concurrently Discussion with Professor Chen Haisong. Theoretical Discussion, vol. 6, no. 2, pp. 159, 2018.

[17] The General Provisions of China's 1982 Constitution clearly pointed out that the division of powers between the central and local state institutions requires that under the unified leadership of the central government, the principles of local initiative and enthusiasm should be fully utilized.

[18] Jiang Shuxia. Local Governments in Reform and Opening up: A Sample Survey of Xiamen's Changes in 30 Years. Shanghai: Gezhi Publishing House and Shanghai People's Publishing House, pp. 212, 2009.

[19] Chen Haisong. The Formation and Standardization of the Rule of Law of Political Parties in the Ecological Environment. Law Science, vol. 5, no. 4, pp. 76, 2019. 